\title{
Relation of Normal Childbirth Care Training to Midwives Knowledge and Attitudes at Bebesen Health Center Bebesen District of Central Aceh Regency
}

\section{in 2021}

\section{Hasritawati $^{1^{*}}$, Barirah Madeni ${ }^{1}$}

${ }^{1}$ Diploma of Midwifery Study Program, Poltekes Kemenkes Aceh, Aceh Tengah, Indonesia

\section{A R T I C L E I N F O \\ Keywords: \\ APN \\ Knowledge \\ Attitude \\ *Corresponding author: \\ Hasritawati \\ E-mail address: \\ hasritawati90@gmail.com \\ All authors have reviewed and approved the final version of the manuscript.}

\section{https://doi.org/10.32539/bsm.v5i11.426}

\begin{abstract}
A B S T R A C T
Background. Mortality and morbidity in pregnant and maternity women is a big problem in developing countries. In poor countries, about $25-50 \%$ of deaths of women of childbearing age are caused by pregnancy-related causes. It is estimated that every year 585,000 women die from pregnancy and childbirth. $99 \%$ of these deaths occur in developing countries. According to WHO, $60-80 \%$ of maternal deaths are caused by bleeding during childbirth, obstructed labor, sepsis, high blood pressure during pregnancy, and complications from unsafe abortion. The purpose of this study was to determine the relationship between normal delivery care (APN) training on the knowledge and attitudes of midwives at the Bebesen Health Center, Bebesen District, Central Aceh Regency in 2020. Methods. The research method uses an analytical survey method with a cross sectional approach, which is a study to study the dynamics of the correlation between risk factors and effects, by approaching, observing or collecting data at once. The population in this study was all 63 midwives. The sampling method uses a total sampling technique that uses all members of the population as a sample. Data collection was carried out from November 14-16, 2020. Results. The results showed that from the analysis obtained a value for the $\mathrm{p}$-value of good knowledge as many as 20 respondents (31.7\%) and a positive attitude that is as many as 32 respondents $(50.8 \%)$. Conclusion. There is a relationship between normal delivery care training (APN) with knowledge with a $p$ value of $0.014(\mathrm{p}<0.05)$ and normal delivery care (APN) with changes in the attitude of midwives with a p value of $0.00(\mathrm{p}<0.05)$ in Bebesen Public Health Center, Bebesen District, Central Aceh Regency.
\end{abstract}

\section{Introduction}

Mortality and morbidity in pregnant and maternity women are a big problem in developing countries. In poor countries, about $25-50 \%$ of deaths of women of childbearing age are caused by pregnancy-related causes. Death during childbirth is usually a major factor in the mortality of young women at their peak of productivity. ${ }^{1}$

It is estimated that every year 585,000 women die from pregnancy and childbirth. 99\% of these deaths occur in developing countries. Women in West Africa, East Africa and some Asian countries face a very high risk of maternal death. According to WHO, 60-80\% of maternal deaths are caused by bleeding during childbirth, obstructed labor, sepsis, high blood pressure during pregnancy, and complications from unsafe abortion. The occurrence of complications during pregnancy/delivery is often unpredictable and occurs several hours or days after delivery. ${ }^{1}$

The risk of death due to pregnancy, childbirth or the puerperium as well as the baby can be reduced if there are efforts to prepare for delivery and facilitate access to basic services. ${ }^{2}$

The birth attendants do not yet have standard normal delivery skills to ensure the safety and comfort of the mother during childbirth. The collaboration designed a clinical training which is expected to be able to improve the performance of the birth attendants. ${ }^{3}$ 
The Ministry of Health of the Republic of Indonesia, the Indonesian Obstetrics and Gynecology Association (POGI), the Indonesian Midwives Association (IBI), the National Network of Reproductive Health Clinic Training (JNPK-KR) with technical assistance from JHPIEGO and PRIME identified performance gaps that could affect the quality of services for mothers pregnant and giving birth. Based on these findings, the collaboration team has designed a clinical training that is expected to be able to improve the performance of birth attendants known as Normal Delivery Care (APN). ${ }^{2}$

The purpose of normal delivery care is to strive for survival and achieve a high degree of health for both mother and baby. Through various integrated and complete efforts and minimal interventions so that the principles of safety and quality of service can be maintained at an optimal level. The main focus of normal delivery care is preventing complications. This is a paradigm shift from waiting and handling complications, to preventing complications that may occur. Preventing complications during delivery and after the baby is born will reduce maternal and newborn morbidity and mortality. ${ }^{2}$

\section{Methods}

This research uses an analytical survey research method with a cross sectional approach, namely a study to study the dynamics of the correlation between risk factors and effects, by approach, observation or data collection at one time. To find out the relationship between normal delivery care training (APN) on the knowledge and attitudes of midwives at the Bebesen Health Center, Bebesen District, Central Aceh Regency in 2020 which was held on November 14-16, 2020.

The population in this study was all 63 midwives. The sampling method used in this study was total sampling, namely in this study the researcher used all members of the population as a sample at the Bebesen Health Center, Bebesen District, Central Aceh Regency in 2020 .

The data collection includes primary data and secondary data, primary data is data that is directly obtained by distributing questionnaires that contain questions which will then be filled in by the respondent. This data collection was assisted by 2 enumerators who have been trained. Secondary data is data that has been available at the Bebesen Health Center, Bebesen District, Central Aceh Regency.

Data analysis in this study includes univariate analysis, data analysis is carried out by describing descriptively to see the frequency distribution of the variables studied, both independent and dependent. For this analysis all tables are made in the form of a frequency distribution table. And bivariate analysis is carried out to determine the relationship between the independent variable (independent) and the dependent variable (dependent). By using the Chi-Square test with the SPSS (Statistical Product and Service Solution) program, the decision to test the hypothesis is based on the 95\% significance level (significance) with a $\mathrm{p}$ value of $<0.05 .4 .5$

\section{Results}

\section{Normal Delivery Care (APN)}

Table 1. Frequency of midwives who attended normal delivery care (APN) training at the Bebesen Health Center, Bebesen District, Central Aceh Regency in 2020

\begin{tabular}{|c|c|c|c|}
\hline No & Normal Delivery Care & Frequency & $\%$ \\
\hline 1 & Ever & 37 & 58.7 \\
\hline 2 & Never & 26 & 41.3 \\
\hline & Total & 63 & 100 \\
\hline
\end{tabular}

Based on table 1 above, of the 63 respondents, most of the respondents had attended APN training, namely
37 people (41.3\%). 


\section{Knowledge}

Table 2. Frequency distribution of midwife knowledge about Normal Delivery Care (APN) at Bebesen Health Center Bebesen District, Central Aceh Regency in 2020

\begin{tabular}{|c|l|c|c|}
\hline No & \multicolumn{1}{|c|}{ Knowledge } & Frequency & $\%$ \\
\hline 1 & High & 26 & 41.3 \\
\hline 2 & Medium & 28 & 44.4 \\
\hline 3 & Low & 9 & 14.3 \\
\hline & Total & 63 & 100 \\
\hline
\end{tabular}

Based on Table 2 above, from 63 respondents, most category, which was 28 people (44.4\%). of the respondents' knowledge was in the medium

\section{Attitudes}

Table 3. Frequency distribution of midwives' attitudes about Normal Delivery Care (APN) at Bebesen Health Center Bebesen District, Central Aceh Regency in 2020

\begin{tabular}{|c|l|c|c|}
\hline No & Attitude & Frequency & \% \\
\hline 1 & Positive & 35 & 55.6 \\
\hline 2 & Negative & 28 & 44.4 \\
\hline & Total & 63 & 100 \\
\hline
\end{tabular}

Based on table 3 above, of the 63 respondents, most normal delivery care, as many as 35 people (55.6\%).

of the midwives had a positive attitude in carrying out

\section{Bivariate Analysis}

\section{Relationship between APN training and midwife knowledge}

Table 4. Relationship of Normal Childbirth Care (APN) with midwife knowledge at Bebesen Health Center Bebesen District, Central Aceh Regency in 2020

\begin{tabular}{|c|c|c|c|c|c|c|c|c|}
\hline \multirow{3}{*}{ No } & \multirow{3}{*}{ Knowledge } & \multicolumn{4}{|c|}{ APN } & \multirow{2}{*}{\multicolumn{2}{|c|}{ Total }} & \multirow[b]{2}{*}{ P Value } \\
\hline & & \multicolumn{2}{|c|}{ Ever } & \multicolumn{2}{|c|}{ Never } & & & \\
\hline & & $\mathbf{f}$ & $\%$ & $\mathbf{f}$ & $\%$ & $\mathbf{F}$ & $\%$ & \multirow{5}{*}{0.014} \\
\hline 1 & High & 20 & 31.7 & 6 & 9.5 & 26 & 41.3 & \\
\hline 2 & Medium & 15 & 23.8 & 13 & 20.6 & 28 & 44.4 & \\
\hline \multirow[t]{2}{*}{3} & Low & 2 & 3.2 & 7 & 11.1 & 9 & 14.3 & \\
\hline & Total & 37 & 58.7 & 26 & 41.3 & 63 & 100 & \\
\hline
\end{tabular}

Based on table 4 of the 63 respondents the majority of respondents have high knowledge and have attended APN training as many as 20 people (31.7\%).

The results of statistical analysis using the test chi square showed that the relationship was significant, where the $\mathrm{p}$ value was $0.014(\mathrm{P}<0.05)$. This means that the research hypothesis which states that there is a relationship between APN training and knowledge is proven or acceptable. 
The relationship between normal delivery care training and the attitude of the midwife.

Table 5. Relationship between normal delivery care training and knowledge of midwives at Bebesen Health Center, Bebesen District, Central Aceh Regency in 2020.

\begin{tabular}{|c|c|c|c|c|c|c|c|c|}
\hline \multirow{3}{*}{ No } & \multirow{3}{*}{ Attitude } & \multicolumn{4}{|c|}{ APN } & \multirow{2}{*}{\multicolumn{2}{|c|}{ Total }} & \multirow{2}{*}{ P Value } \\
\hline & & \multicolumn{2}{|c|}{ Ever } & \multicolumn{2}{|c|}{ Never } & & & \\
\hline & & $\mathbf{f}$ & $\%$ & $\mathbf{F}$ & $\%$ & $\mathbf{F}$ & $\%$ & \multirow{3}{*}{0.00} \\
\hline 1 & Positive & 32 & 50.8 & 3 & 4.8 & 35 & 55.6 & \\
\hline \multirow[t]{2}{*}{2} & Negative & 5 & 7.9 & 23 & 36.5 & 28 & 44.4 & \\
\hline & Total & 37 & 58.7 & 26 & 41.3 & 63 & 100 & \\
\hline
\end{tabular}

Based on table 5 it can be seen that from 63 respondents the majority of respondents have a positive attitude and have attended APN training, namely as many as 32 people (50.8\%).

The results of statistical analysis using the chi-

\section{Discussion}

The relationship between normal delivery care training (APN) and the knowledge of the midwife

The results of statistical analysis in table 4 using the chi square test show that the relationship is significant, where the $\mathrm{p}$ value is $0.014(\mathrm{P}<0.05)$. This means that the research hypothesis which states that there is a relationship between APN training and midwife's knowledge is proven or acceptable.

In accordance with the results of Theresia's research (2004), where the results of the study show that there is a relationship between APN training and midwife knowledge. Significant variables are knowledge, attitudes and skills between health workers who have not attended training and health workers who have attended normal delivery care (APN) training. This is proven by the value of $\mathrm{p}=0.000<=0.05$ on the knowledge variable and the value of $\mathrm{p}=0.000<=0.05$ on the attitude variable, and the value of $\mathrm{p}=0.000<=$ 0.05 on the skill variable.

In accordance with the results of Theresia's research (2004), where the results of the study show that there is a relationship between APN training and midwife knowledge. Significant variables are knowledge, attitudes and skills between health workers who have not attended training and health workers who have attended normal delivery care (APN) training. This is proven by the value of $\mathrm{p}=0.000<=0.05$ on the square test showed that the relationship was very significant where the $\mathrm{p}$ value was $0.00(\mathrm{P}<0.05)$. This means that the research hypothesis which states that there is a relationship between training and attitude change is proven or acceptable.

knowledge variable and the value of $\mathrm{p}=0.000<=0.05$ on the attitude variable, and the value of $\mathrm{p}=0.000<=$ 0.05 on the skill variable.

In accordance with the opinion of Notoadmodjo (2013) knowledge is the result of knowing and this occurs after people have sensed a certain object. Sensing occurs through the human senses, namely the senses of sight, hearing, smell, taste and touch. Most of human knowledge is obtained through the eyes and ears. ${ }^{6-10}$

Training is one source of information, in this particular case related to normal delivery care (APN). Because most of the respondents had attended normal delivery care (APN) training, this resulted in an increase in the knowledge of the midwives so that the results of this study showed that there was a relationship between the two.

\section{The Relationship of Normal Childbirth Care (APN) training with midwives' attitudes}

The results of statistical analysis in table 5 using the test chi-square show that the relationship is significant where the $\mathrm{p}$ value is $0.00(\mathrm{P}<0.05)$. This means that the research hypothesis which states that there is a relationship between training and the attitude of midwives in normal delivery care (APN) is proven or acceptable. This research is supported by the results of Chotimah's research (2008) where the 
results of the analytical analysis prove that there is a very significant effect of APN training on knowledge, judging by the $\mathrm{p}$ value $=0.000(0.05)$, it is evident that there is a comparison between midwives who have been trained with midwives who have not received APN training. The results of the Skills analysis prove that there is a very significant effect of APN training, choose the value of $\mathrm{p}=0.000(0.05)$, it is proven that there is an increase in the skills of midwives who receive APN training compared to midwives who have not received APN training. From the attitude analysis analysis, it was proven that there was a very significant effect of APN training on attitudes, seen the $\mathrm{p}$ value $=0.000$ (0.05), it was evident that there was a change in the attitude of midwives who had received APN training compared to midwives who had not received training in handling patients.

In accordance with what was stated by Hardi (2013), where the purpose of training is to help company employees improve their knowledge, skills and attitudes at work so that they are ready and able to carry out their work tasks efficiently and effectively within the company or workplace. The information or knowledge provided in the training has an impact on changes in the attitudes of the participants in this case is a change in attitude in carrying out normal delivery care (APN).11-15

\section{Conclusion}

There is a relationship between normal delivery care training (APN) and the knowledge of the midwife in carrying out normal delivery care. In addition, there is also a relationship between normal delivery care (APN) training and changes in the attitude of the midwife.

\section{References}

1. Prawihardjo, S. National reference book for health and neonatal services. JNPKKR-POGI.
Jakarta. 2014.

2. Indonesian Ministry of Health. Normal childbirth care. Indonesian Ministry of Health. Jakarta. 2017.

3. Mochtar, A. APN and LSS training for midwives. Special Edition.IBI. Jakarta. 2015.

4. Budiarto, E. Biostatics for Medicine and Public Health. EGC. Jakarta. 2012.

5. Hastono, SP data analysis module. Faculty of Public Health, University of Indonesia, Jakarta. 2007.

6. Hendeson, C. Textbook of midwifery concepts. EGC Medical Book Publisher. Jakarta. 2012.

7. Koesno, Healthy village, Alert village, Healthy mother, Healthy child, Healthy nation. Midwife Magazine Publisher. Jakarta. 2008.

8. Mochtar, R. Synopsis of obstetrics. EGC Medical Book Publisher. Jakarta. 2015;1

9. Niven; Neil. Health psychology. EGC. Jakarta. 2013.

10. Notoadmodjo, S, Behavior and health education. PT. Rineka Cipta. Jakarta. 2013.

11. PP. IBI. Midwife as a profession. Jakarta. 2009.

12. Midwifery science. Sarwono Praworohardjo Bina Pustaka Foundation. Jakarta. 2014.

13. Purwanto, H. Introduction to human health behavior. EGC. Jakarta. 2012.

14. Riduwan, MBA. Fundamentals of statistics. Alphabet. Jakarta. 2012.

15. Sastroasmoro, Fundamentals of clinical research methodology.CV. Sago Seto. Jakarta. 2014. 